\title{
Apoptosis signal-regulating kinase 1 mediates the inhibitory effect of hepatocyte nuclear factor-4a on hepatocellular carcinoma
}

\author{
Cai-Feng Jiang ${ }^{1, *}$, Liang-Zhi Wen ${ }^{1, *}$, Chuan Yin ${ }^{1,}{ }^{*}$, Wen-Ping $X u^{1}$, Bin Shi ${ }^{1}$, Xin Zhang ${ }^{1}$, \\ Wei-Fen Xie ${ }^{1}$ \\ ${ }^{1}$ Department of Gastroenterology, Changzheng Hospital, Second Military Medical University, Shanghai 200003, China \\ *These authors contributed equally to this work
}

Correspondence to: Wei-Fen Xie, e-mail: weifenxie@medmail.com.cn

Keywords: apoptosis signal-regulating kinase 1, hepatocyte nuclear factor 4a, hepatocellular carcinoma, mitogen-activated protein kinases, differentiation therapy

Received: October 16, 2015 Accepted: March 16, $2016 \quad$ Published: March 30, 2016

\section{ABSTRACT}

Previous studies provided substantial evidence of a striking suppressive effect of hepatocyte nuclear factor 4a (HNF4a) on hepatocellular carcinoma (HCC). Apoptosis signal-regulating kinase 1 (ASK1) is involved in death receptor-mediated apoptosis and may acts as a tumor suppressor in hepatocarcinogenesis. However, the status and function of ASK1 during HCC progression are unclear. In this study, we found that HNF4a increased ASK1 expression by directly binding to its promoter. ASK1 expression was dramatically suppressed and correlated with HNF4a levels in HCC tissues. Reduced ASK1 expression was associated with aggressive tumors and poor prognosis for human HCC. Moreover, ASK1 inhibited the malignant phenotype of HCC cells in vitro. Intratumoral ASK1 injection significantly suppressed the growth of subcutaneous HCC xenografts in nude mice. More interestingly, systemic ASK1 delivery strikingly inhibited the growth of orthotopic HCC nodules in NOD/SCID mice. In addition, inhibition of endogenous ASK1 partially reversed the suppressive effects of HNF4a on HCC. Collectively, this study highlights the suppressive effect of ASK1 on HCC and its biological significance in HCC development. These outcomes broaden the knowledge of ASK1 function in HCC progression, and provide a novel potential prognostic biomarker and therapeutic target for advanced HCC.

\section{INTRODUCTION}

Hepatocellular carcinoma (HCC) is one of the most common malignant tumors worldwide [1]. Although progression of medical technology has led to great developments in HCC diagnosis and treatment, the long-term survival of HCC patients remains unsatisfactory [2]. Hence, strategies to inhibit HCC progression are urgently needed.

Hepatocyte nuclear factor $4 \alpha(\mathrm{HNF} 4 \alpha)$, a principal member of the hepatic transcription factor network, plays an indispensable role in regulating hepatic lineage differentiation and in maintaining liver function [3, 4]. It is also linked to a variety of human diseases including diabetes mellitus, colitis, and cancer [5-8]. It has been reported that transient suppression of HNF4 $\alpha$ initiates hepatocellular transformation [9] and HNF4 $\alpha$ knockout in adult hepatocytes leads to hepatocyte proliferation and promotes the development of HCC in mice [10], suggesting that HNF $4 \alpha$ plays a critical role in liver carcinogenesis. Our previous studies indicate that HNF4 $\alpha$ expression is decreased gradually during hepatocarcinogenesis after diethylnitrosamine (DEN) administration in rats [11] and that reduced $\mathrm{HNF} 4 \alpha$ expression is associated with aggressive behavior and poor prognosis in HCC patients [12]. Furthermore, forced HNF4 $\alpha$ overexpression induced the hepatoma cell differentiation into hepatocytes and suppressed in vivo HCC growth and metastasis [12, 13]. In addition, HNF4 $\alpha$ administration attenuated liver fibrosis in rats [14]. More recently, molecular mechanisms, such as miRNA cascades and inflammatory signaling pathways, through which HNF4 $\alpha$ inhibits HCC have been clarified $[9,12,15,16]$. However, as a key hepatic transcription factor, whether other signaling pathways are involved in the mechanisms of HNF $4 \alpha$ need for further study.

Apoptosis signal-regulating kinase 1 (ASK1), also known as mitogen-activated protein $3 \mathrm{~K} 5$, is a member 
of the mitogen-activated protein kinase kinase kinase (MAP3K) family that selectively activates downstream mitogen-activated protein kinases (MAPKs), c-Jun $\mathrm{N}$-terminal kinases (JNKs), and p38 MAPKs in response to various cellular stresses $[17,18]$. In particular, ASK1 has been identified as a key determiner of cell death via triggering cell apoptosis. Interestingly, ASK1 has also been reported to promote cellular differentiation. Recent studies revealed that ASK1 may be involved in differentiation process in diverse cell types, including keratinocytes [19], chondrocytes [20] and stem cells [21]. On the other hand, substantial evidence demonstrate that a number of cancers are intimately related to ASK1 mediated cascades [22-24]. However, the role of ASK1 in malignances remains controversial [25-30]. Nakagawa et al. showed that ASK1-deficient mice had increased susceptibility to DEN-induced HCC [31]. It was also reported that ASK1-p38 MAPK signaling was implicated in DEN-induced hepatocellular carcinogenesis in Toll-like receptor 2-deficient mice [32]. These data suggest that ASK1 plays an important role in hepatocarcinogenesis, yet the role for ASK1 as a drug target in $\mathrm{HCC}$ and the significance of ASK1 expression in patients are obscure.

In this study, we demonstrate the prognostic value of ASK1 in HCC patients and the inhibitory effect on HCC progression both in vitro and in vivo. These results not only deepen our understanding of the biological significance of ASK1 but also provide a promising new therapeutic target and a novel prognostic biomarker for HCC.

\section{RESULTS}

\section{HNF4 $\alpha$ regulates MAPK signaling and activates ASK1 expression}

HNF $4 \alpha$ is regarded as a key suppressor of hepatic carcinoma. To explore the mechanisms underlying the inhibitory effect of HNF4 $\alpha$ on HCC, a cDNA microarray was performed to obtain gene expression profiles in Hep3B cells after recombinant adenoviruses AdHNF4 $\alpha$ infection to induce $\mathrm{HNF} 4 \alpha$ overexpression. $\mathrm{HNF} 4 \alpha$ positively regulated 1218 mRNAs and negatively regulated 1411 mRNAs for more than 2 times (The entire dataset is available at NCBI Gene Expression Omnibus http://www. ncbi.nlm.nih.gov/geo/ with accession number GSE66785). Pathway analysis using the DAVID database [33] showed that many differentially expressed genes were known to be involved in hepatocyte function, such as complement and coagulation cascades, metabolism, Type 2 diabetes mellitus, etc. Interestingly, a cluster of genes in cancerassociated pathways, such as the p53 and MAPK signaling pathways, were also regulated by HNF4 $\alpha$ (Supplementary Figure S1). As the MAPK signal transduction pathway is crucial for determining cell differentiation [19], we then focused on its role in HNF4 $\alpha$-mediated cell differentiation. In total, 41 genes in the MAPK signaling pathway were differentially regulated by $\mathrm{HNF} 4 \alpha$ in Hep3B cells. 14 genes were downregulated and 27 were upregulated (Figure 1A). The significant increase in $A S K 1$ expression was particular interesting because it is a key mediator of MAPK signaling and is reported to be involved in the pathogenesis of many tumors. We then validated the effect of HNF $4 \alpha$ on $A S K 1$ expression by real-time polymerase chain reaction (RT-PCR) and Western blotting. ASK1 expression appeared to be sensitive to the level of $\mathrm{HNF} 4 \alpha$. It was increased by HNF $4 \alpha$ overexpression and decreased by HNF4 $\alpha$ knockdown (Figure 1B and Supplementary Figure S2). Consistently, Western blot analysis showed that phosphorylation of the JNK and p38 (MAPKs downstream of ASK1) were also increased after HNF4 $\alpha$ overexpression (Figure 1C). This result confirmed that MAPKs can be activated by HNF4 $\alpha$. We then used the JASPAR database [34] to predict the site of $\mathrm{HNF} 4 \alpha$ response element (HNF4 $\alpha-\mathrm{RE}$ ) in the promoter region of $A S K 1$ gene. One HNF4 $\alpha$-RE was identified when the profile score threshold was set to $80 \%$ (Supplementary Figure S3); this was confirmed by chromatin immunoprecipitation (ChIP) assay. As shown in Figure 1D, the binding of HNF4 $\alpha$ to $A S K 1$ promoter was highly enriched in Hep3B cells with HNF $4 \alpha$ overexpression. In contrast, knockdown of HNF4 $\alpha$ by small interfering RNA (siRNA) in Hep3B cells substantially decreased the binding enrichment. These data suggest direct binding between endogenous ASK1 and HNF $4 \alpha$ in HCC cells. To further determine the effect of HNF $4 \alpha$ on $A S K 1$ transactivation, luciferase reporter plasmids containing the $A S K 1$ promoter with the HNF4 $\alpha$ RE were transfected into AdHNF4 $\alpha$-infected Hep3B and Huh7 cells. The reporter assay showed that ectopic HNF4 $\alpha$ expression increased the transcriptional activity of $A S K 1$ promoter, and that this effect was significantly impaired by mutation of the HNF4 $\alpha-$ RE (Figure $1 \mathrm{E}$ and Supplementary Table S1). Together, these data reveal that HNF $4 \alpha$ activates $A S K 1$ transcription by binding to its promoter.

\section{Reduced ASK1 expression is associated with aggressive clinicopathological features and poor prognosis for human $\mathrm{HCC}$}

We next examined ASK1 and HNF4 $\alpha$ mRNA levels in HCC tissue specimens and their surrounding noncancerous tissue (NT) from 60 patients (defined as Group 1) by RT-PCR. Compared with NT, HNF4 $\alpha$ mRNA was downregulated in 45 of 60 cases $(75 \%)$ and ASK1 mRNA was downregulated in 44 of 60 cases $(73.33 \%$; Figure 2A). Moreover, ASK1 expression was positively correlated with HNF4 $\alpha$ levels in HCC patients $(r=0.605$, $P<0.0001$; Figure 2B). The clinicopathological significance of ASK 1 and HNF4 $\alpha$ expression was further analyzed. The median mRNA level of ASK1 and HNF4 $\alpha$ was chosen as the cutoff point, leaving 30 cases in each group (Supplementary Tables S2-S3). ASK1 and 
A

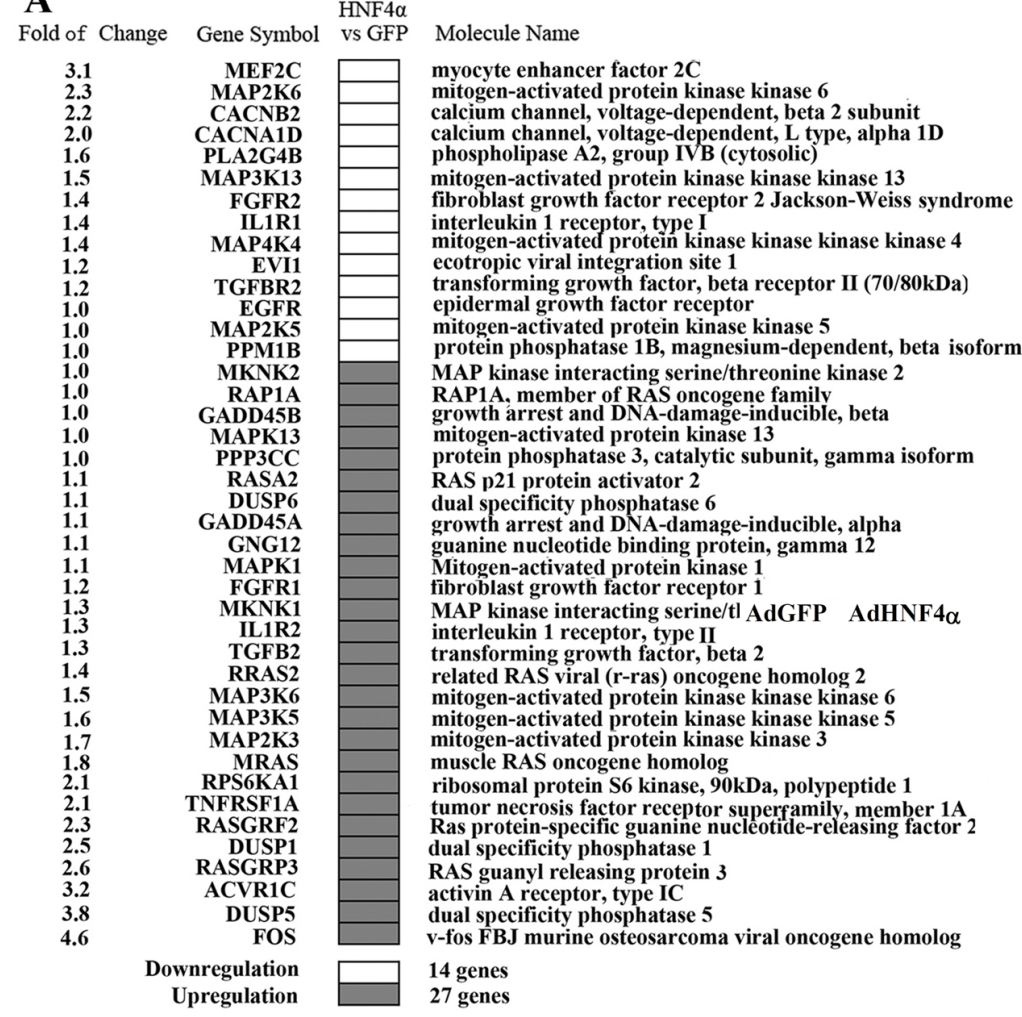

B

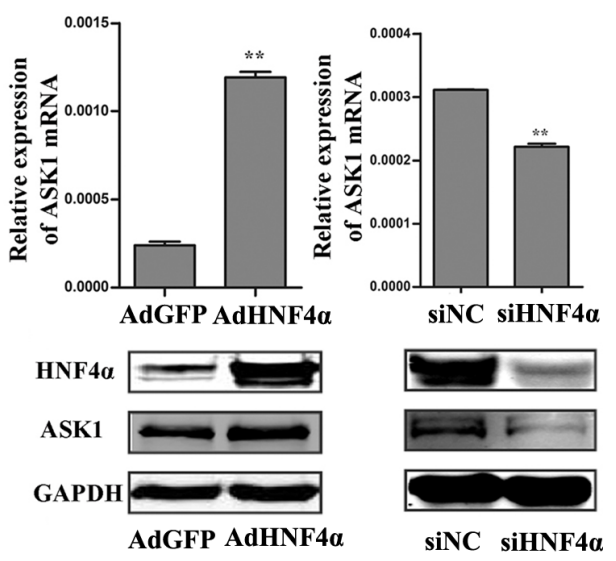

C

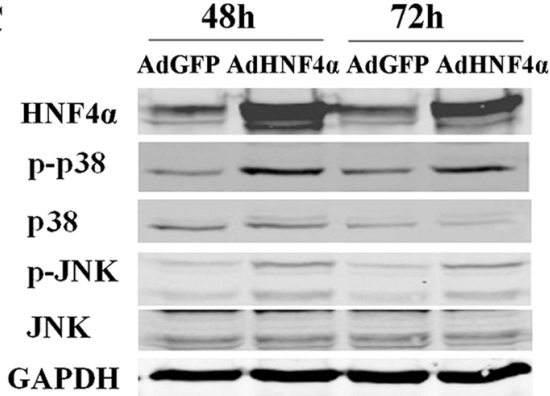

D
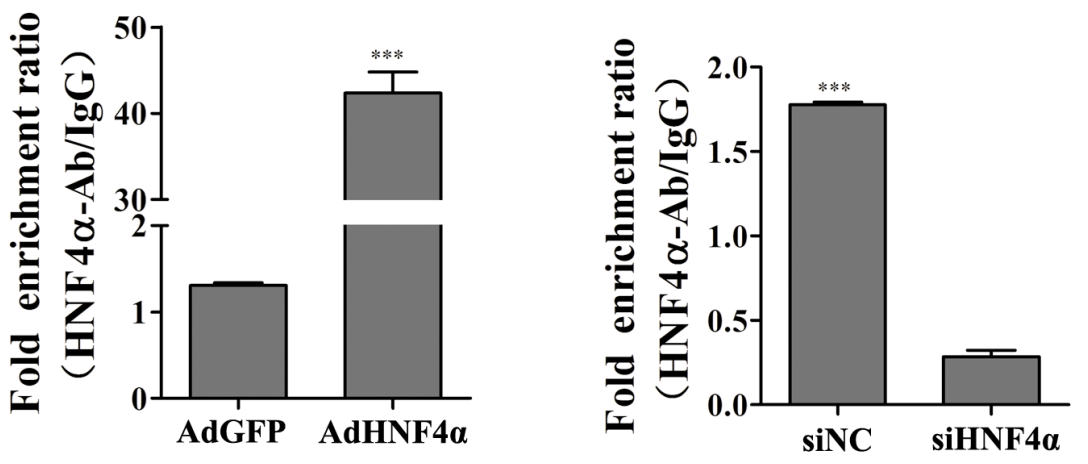

$\mathbf{E}$
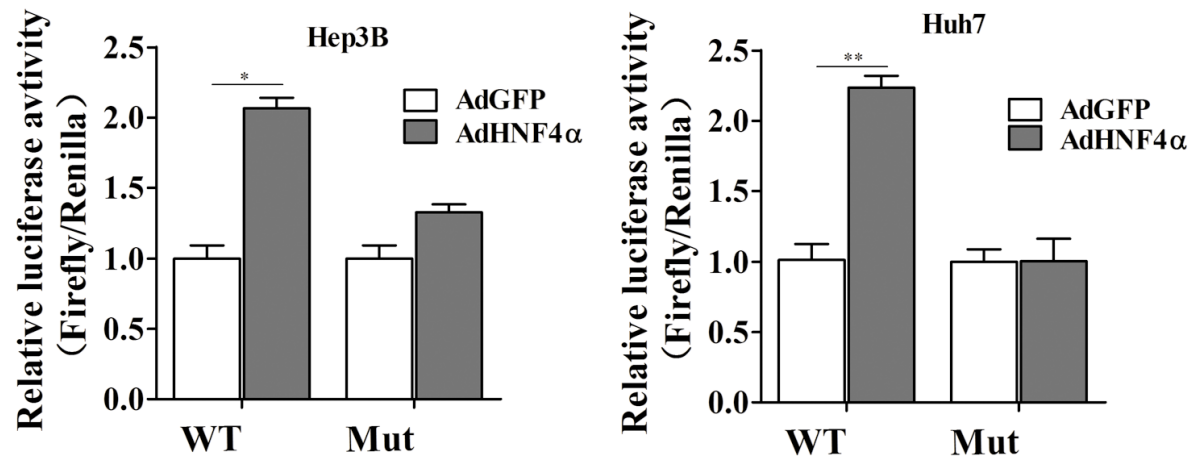

Figure 1: HNF4 $\alpha$ regulates the MAPK signaling pathway and activatesASK1 by binding to its promoter.(A)cDNAmicroarray analysis identified downregulated and upregulated MAPK signaling pathway genes in Hep3B cells infected with AdHNF4 $\alpha$ or AdGFP after $72 \mathrm{~h}$. (B) RT-PCR and Western blot analysis of ASK1 expression in AdHNF4 $\alpha$-infected or siHNF4 $\alpha$-transfected Hep3B cells after $72 \mathrm{~h}$. (C) Western blot analysis of phospho- (p-)p38, p38, p-JNK, and JNK expression in AdHNF4a-infected Hep3B cells after $48 \mathrm{~h}$ and $72 \mathrm{~h}$. (D) ChIP assays revealed HNF4 $\alpha$ binding to $A S K 1$ promoter region. RT-PCR was performed to examine DNA fragments immunoprecipitated by the anti-HNF4 $\alpha$ antibody with primers targeting the HNF4 $\alpha$ response element. DNA immunoprecipitated using normal rabbit $\operatorname{IgG}(\operatorname{IgG})$ was used as the control. (E) Luciferase activity in HCC cells for a reporter plasmid harboring the HNF4 $\alpha$ response element derived from the ASK1 promoter. Mutation of the HNF4 $\alpha$ response element (Mut) abolished HNF4 $\alpha$ transcriptional activity. Each value represents the mean $\pm \mathrm{SD}$ of triplicate experiments. Data represent the mean $\pm \mathrm{SD},{ }^{*} P<0.05,{ }^{* *} P<0.01$. 
HNF4 $\alpha$ mRNA levels were inversely correlated with $\alpha$-fetoprotein (AFP) mRNA levels (Figure 2C, $P=0.0028$ and Supplementary Figure S4A). More interestingly, low ASK1 mRNA expression was also associated with an aggressive HCC phenotype, including larger tumor size $(P=0.034)$, advanced tumor stage $(P=0.009)$ and an absence of tumor encapsulation $(P=0.013$; Supplementary Table S2). Consistently, reduced HNF4 $\alpha$ levels correlated well with larger tumor size $(P=0.0001)$ and advanced tumor stage $(P=0.022$; Supplementary Table S3). In addition, low ASK1 and HNF4 $\alpha$ expression were more likely in human HCC specimens containing high levels of AFP, tumor diameter $>5 \mathrm{~cm}$ and advanced tumor stage, vice versa (Supplementary Figure S4B-S4D).

We then examined the levels of HNF4 $\alpha$, ASK1 and p-ASK1 in three HCC clinical samples by immunohistochemistry. As shown in Supplementary Figure S5, HNF4 $\alpha$ was significantly decreased in HCC. Consistently, both ASK1 and p-ASK1 were also reduced in HCC compared with NT, further suggested that the expression of AKS1 was correlated with HNF4 $\alpha$. As ASK1 is activated by phosphorylation, the data also indicated that the activity of ASK1 also reduced in HCC.

To further determine whether ASK1 low-expression predicts poor prognosis of HCC patients, a HCC tissue microarray was performed to detect ASK1 protein level. Consistent with the data of ASK1 mRNA levels in Group 1, ASK1 protein levels was downregulated in 53 of 86 cases $(61.63 \%)$ compared with NT. The median expression value of ASK1 protein was used as the cut-off to separate patients into groups with high or low ASK1 levels. Furthermore, reduced ASK1 protein expression was more frequent in HCCs with a tumor diameter $>5$ $\mathrm{cm}$ than in those with a tumor diameter $\leq 5 \mathrm{~cm}(63 \%$ versus $32 \%$; Figure 2D, $P<0.0001$ ). In addition, patients with an advanced tumor stage or microvascular invasion showed relatively low ASK1 protein levels (Figure 2E, $P<0.0001$; and Figure 2F, $P<0.0001$ ) and patients with low ASK1 expression exhibited a much lower overall survival (OS) compared with those with high ASK1 expression (median OS 22 and 47 months, respectively; $P=0.0116$; Figure 2G). More interestingly, ASK1 expression combined with tumor diameter dramatically enhanced the predictive accuracy of prognosis (Figure $2 \mathrm{H}$, $P=0.0095)$.

\section{ASK1 inhibits HCC cell malignancy in vitro}

We next functionally characterized ASK1 by focusing on its effect on HCC cell malignancy. HCC cells infected with recombinant adenoviruses AdASK1 showed a lower proliferation rate and fewer colonies compared with cells infected with control virus AdRFP (Figure 3A, 3B and Supplementary Figure S6A). Moreover, ASK1 overexpression induced more cell death in HCC cells, as assessed by annexin V staining (Supplementary Figure S7). In contrast, inhibition of endogenous ASK1 by siASK1 (Supplementary Figure S8) promoted cell growth and colony formation (Figure 3C, 3D and Supplementary Figure S6A). In addition, ASK1 upregulation significantly inhibited $\mathrm{HCC}$ cell migration and invasion (Figure 3E and Supplementary Figure S6B). In contrast, ASK1 downregulation enhanced $\mathrm{HCC}$ cell migration and invasion (Figure 3F and Supplementary Figure S6B).

\section{ASK1 abolishes tumorigenicity and suppresses growth of HCC in vivo}

To examine the effect of ASK1 on in vivo tumorigenesis, Hep3B or Huh7 cells infected with AdRFP or AdASK1 were subcutaneously transplanted into the flanks of BALB/c nude mice. Six weeks later, xenografts were detected in $80 \%$ (four out of five) mice in the AdRFPHuh7 cell group and in 100\% of Hep3B-inoculated mice. However, no xenografts were observed in mice inoculated with ASK1-infected HCC cells (Figure 4A, 4B). These results demonstrate that ASK1 overexpression can eliminate the tumorigenicity of $\mathrm{HCC}$ cells in vivo.

We then investigated the antitumor effect of ASK1 in an established HCC cell transplant model by subcutaneous injection of Huh7 cells into BALB/c nude mice. Intratumoral injection of AdASK1 significantly reduced the growth and weight of xenografts compared with the control AdRFP group (Figure 4C-4E). ASK1 mRNA expression was striking increased in AdASK1treated tumor nodules (Figure 4F). Immunostaining and TUNEL assay showed that AdASK1 treatment resulted in striking Ki67 downregulation accompanied by more TUNEL-positive cells (Figure 4G and Supplementary Figure S9A).

To further determine the antitumor effect on HCC by ASK1, we investigated the inhibitory effect of systemic AdASK1 injection on orthotopic HCC model in NOD/SCID mice. Luciferase-labeled Huh7 cells were injected into nude mice to establish subcutaneous tumors. Subsequently, the tumors were removed and implanted into NOD/SCID mouse liver to establish an orthotopic HCC model. The xenografts had no difference in luciferase expression before adenovirus treatment. AdASK1-injected mice had notably reduced bioluminescence compared with mice that received control virus (Figure 5A). Consistent with this, tumors from AdASK1-treated mice were significantly smaller than those of AdRFP-treated mice (Figure 5B, 5C). ASK1 mRNA levels were significantly increased in AdASK1-treated group compared with the control group (Figure 5D). Consistently, the number of Ki67-positive cells in tumors of ASK1-treated mice was significantly decreased and, conversely, TUNEL-positive cells were increased (Figure 5E and Supplementary Figure S9B). These experiments together reveal that ASK1 has a therapeutic effect on HCC in vivo. 


\section{ASK1 inhibits HCC by upregulating p38 phosphorylation}

ASK1 is known to activate both the p38 and JNK pathways, which have been implicated in many cancers. To further investigate the mechanism by which ASK1 suppresses HCC, the expression of ASK1 and several key proteins involved in MAPK signaling were measured by Western blot. As expected, p38 phosphorylation was increased in AdASK1-infected Hep3B and Huh7 cells, but JNK phosphorylation was only increased in AdASK1infected Huh7 cells (Figure 6A). Consistent with this, Western blot analysis showed that p38 phosphorylation in tumors from both intratumoral injection and systemic delivery with AdASK1 was activated, but no obvious JNK phosphorylation was observed (Figure 6B, 6C).
A

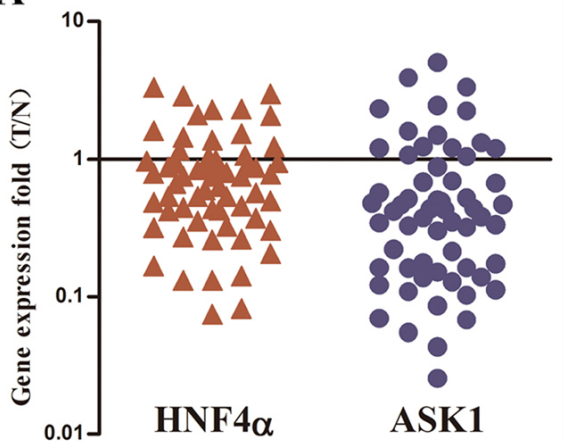

D

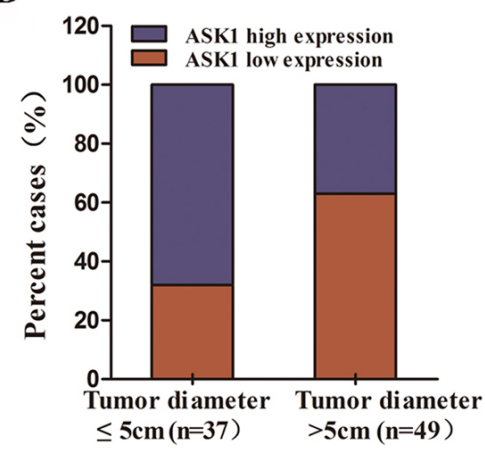

B

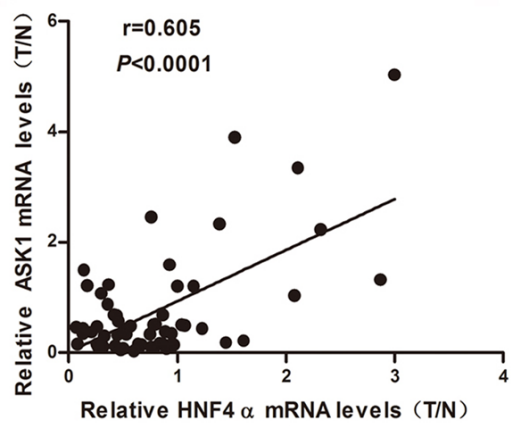

E

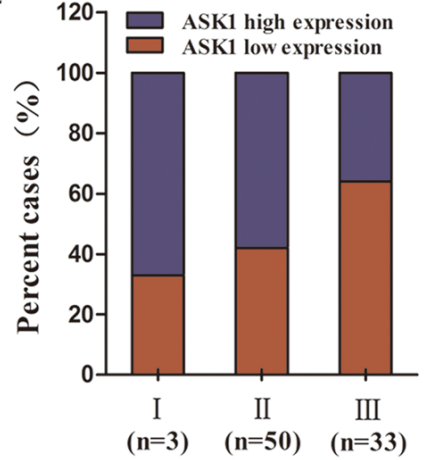

C

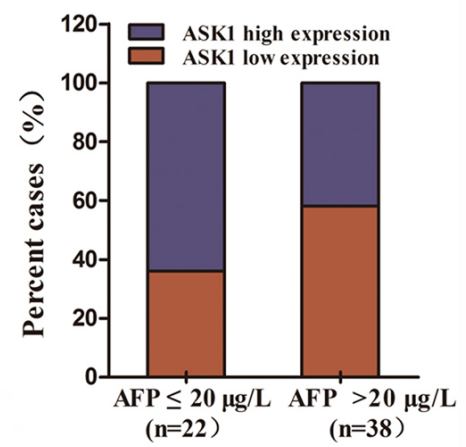

F

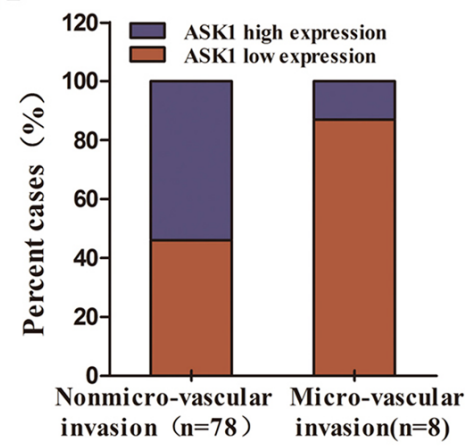

G

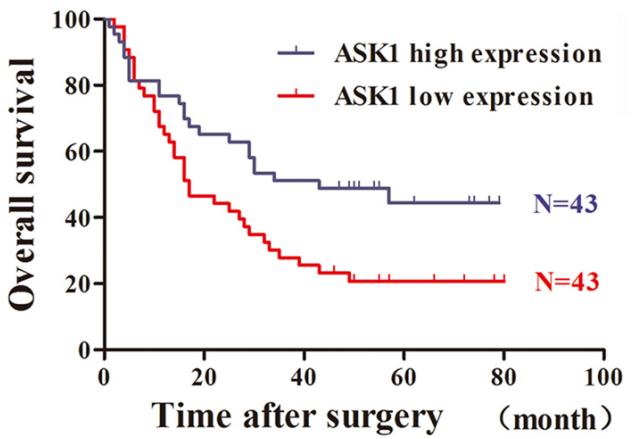

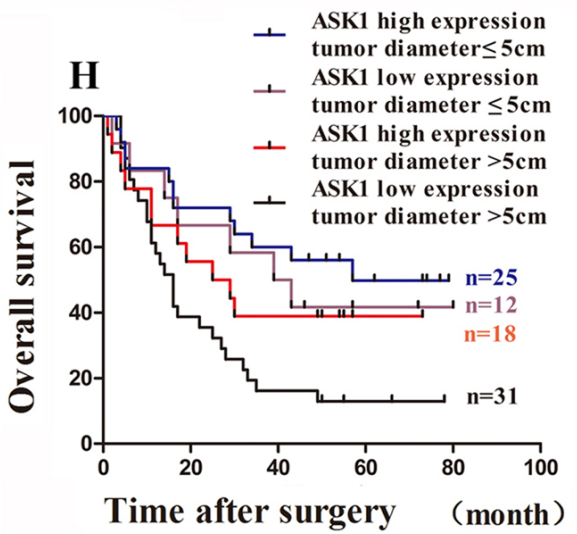

Figure 2: Reduced ASK1 expression is associated with aggressive clinicopathological features and poor prognosis of human HCC. (A) HNF4 $\alpha$ and ASK1 mRNA levels in human HCC samples $(n=60)$, as detected by RT-PCR. The results are presented as the fold change in gene expression in HCC tissue (T) versus noncancerous adjacent tissue $(\mathrm{N})$. (B) The positive correlation between HNF4 $\alpha$ and ASK1 expression in HCC subjects $(r=0.605, P<0.0001, n=60)$. (C) Reduced ASK1 mRNA expression was more common in HCC samples with high AFP mRNA levels than in those with low AFP mRNA levels. Low level: AFP $\leq 20 \mu \mathrm{g} / \mathrm{L}, n=22$; high level: AFP $>20 \mu \mathrm{g} / \mathrm{L}, n=38$. (D-F) Reduced ASK1 protein level is more common in samples from HCC with more aggressive pathological features, including a larger tumor size (D), advanced tumor stage (E), and more microvascular invasion (F). (G) Kaplan-Meier analysis of the overall survival of $86 \mathrm{HCC}$ patients. The median ASK1 protein level for all $86 \mathrm{HCC}$ samples was chosen as the cutoff point. $P=0.0116$ by the logrank test. (H) A combination of ASK1 protein level and tumor diameter enhanced the prognostic accuracy in HCC patients. 
Furthermore, p38 inhibitor SB202190 could partially block ASK1 suppression on HCC cell proliferation (Figure 6D and Supplementary Figure S10). These data reveal that ASK1 may suppress the malignant properties of HCC via increasing p38 phosphorylation.

\section{ASK1 mediates the suppression of HCC by HNF4a}

Given that HNF4 $\alpha$ overexpression activated ASK1 and that ASK1 suppressed the malignant phenotypes of HCC cells, we next determined whether ASK1 mediated the effect of HNF $4 \alpha$ on HCC by a combined loss-of-function and gainof-function approach. HCC cells overexpressing HNF4 $\alpha$ were post-transfected with siASK1 or siNC (Supplementary Figure S11A). As expected, silencing ASK1 expression blocked HNF4 $\alpha$ inhibition of HCC cell proliferation
(Figure 7A). Consistently, repression of cell proliferation by ectopic HNF4 $\alpha$ could be partly reversed by SB202190 (Supplementary Figure S11B). Similarly, flow cytometry showed that the promoting of cell apoptosis by HNF4 $\alpha$ was partially reversed after ASK1 depletion (Figure 7B and Supplementary Figure S11C). A previous study from our laboratory reported that $\mathrm{HNF} 4 \alpha$ re-established the expression profile of characteristic hepatocyte markers in hepatoma cells [13]. Interestingly, ectopic ASK1 expression also promoted the re-expression of some of these hepatocyte marker genes (Figure 7C), seemed to mimic the function of HNF4 $\alpha$. Conversely, the re-expression of hepatocyte marker genes by ectopic HNF4 $\alpha$ was also blocked by siASK1 in Hep3B cells (Figure 7D). Taken together, these data indicate that the HNF $4 \alpha$ inhibition of HCC can be, at least partially, attributed to ASK1 upregulation.
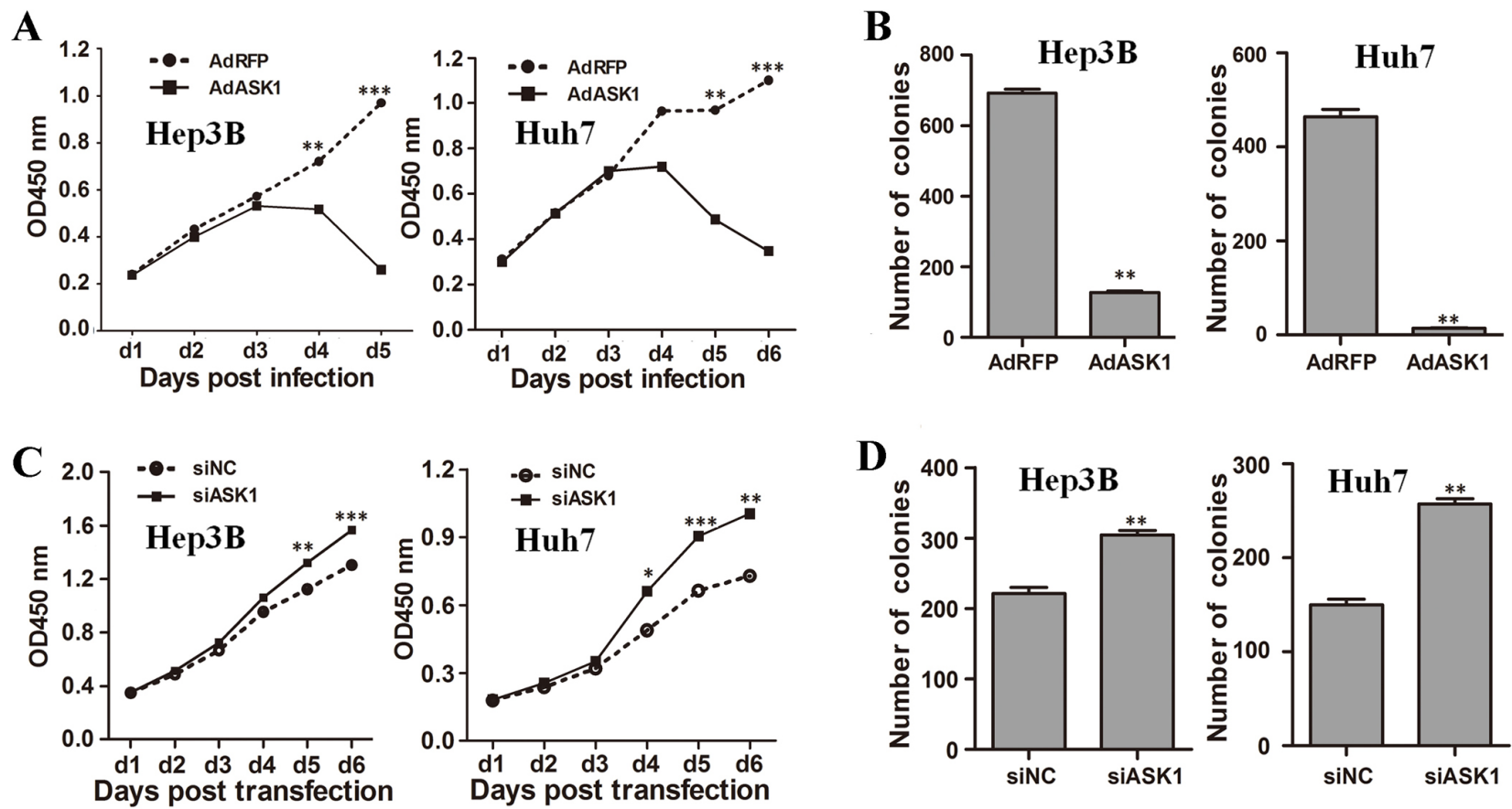

D
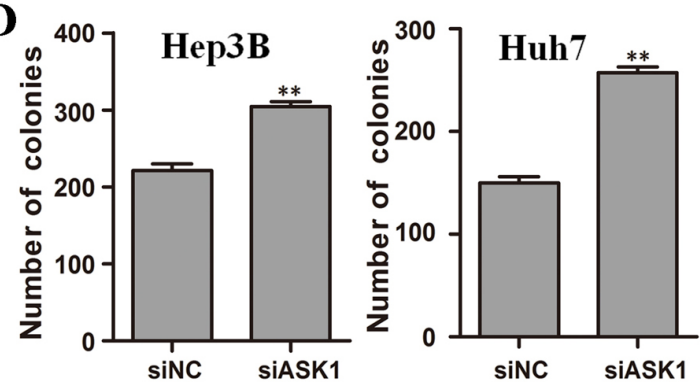

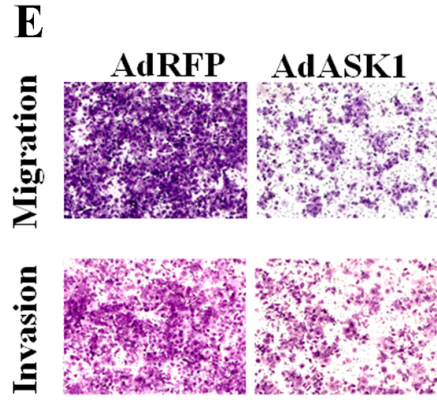

Hep3B
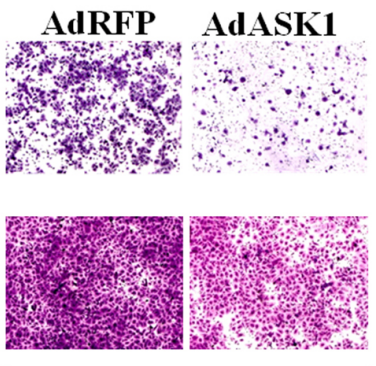

Huh7

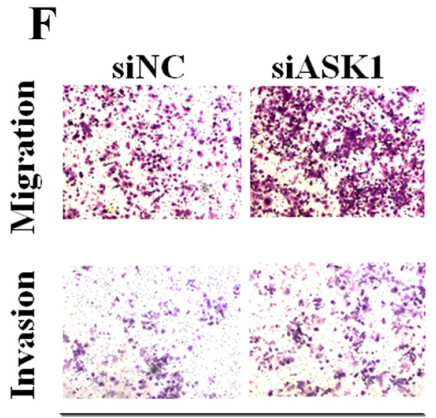

Hep3B
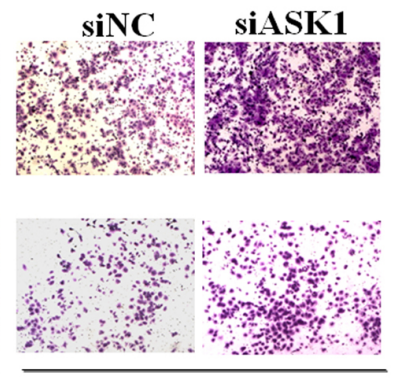

Huh7

Figure 3: ASK1 represses the malignant properties of HCC cells in vitro. (A) The proliferation of HCC cells infected with AdASK1 or AdRFP was measured using the Cell Counting Kit-8. (B) Colony formation assays were performed for Hep3B and Huh7 cells infected with AdASK1 or AdRFP. (C) Proliferation of Hep3B and Huh7 cells transfected with siASK1 or scramble siRNA (siNC). (D) Colony formation assays for Hep3B and Huh7 cells transfected with siASK1 or siNC. (E, F) Migration and invasion were assessed by transwell assays for HCC cells infected with AdASK1 or AdRFP (E) or transfected with siASK1 or siNC (F). Data represent the mean $\pm \mathrm{SD}, * P<0.05, * * P<0.01, * * * P<0.001$. 


\section{DISCUSSION}

A previous study found that ASK1 expression was lower in breast cancer tissues than in normal tissues [35], suggesting that ASK1 has a tumor-suppressing function. In the current study, we proved that low ASK1 expression is correlated with poor prognosis for HCC patients. More interestingly, the malignant properties of HCC cells were also dramatically suppressed by ASK1 overexpression. Furthermore, ASK1 administration showed a dramatic antitumor effect in vivo. These data imply the clinical significance of ASK1 in HCC patients and present a novel target for HCC therapy.

$\mathrm{HNF} 4 \alpha$ is a key transcriptional regulator involved in HCC $[9,10]$. Although some mechanisms involved in the therapeutic effect of HNF $4 \alpha$ on HCC have been comprehended in depth over the past few years $[9,12$, $15,16]$, it is still of considerable interest to identify new pathways, as HNF4 $\alpha$ is a wide-acting transcription factor that regulates numerous downstream targets [36, 37]. In this study, a cluster of genes in pathways linked to distinct categories were affected by HNF4 $\alpha$ overexpression in HCC cells. Specifically, we demonstrated that HNF4a could transcriptionally upregulate $A S K 1$ by directly targeting its promoter in $\mathrm{HCC}$ cells. More importantly, ASK1 downregulation partially abrogated HNF4 $\alpha$ inhibition of HCCs. These data suggest that ASK1 contributes to HNF $4 \alpha$-mediated HCC differentiation, which further elucidates and enriches the mechanism of HNF $4 \alpha$ on HCC.
A

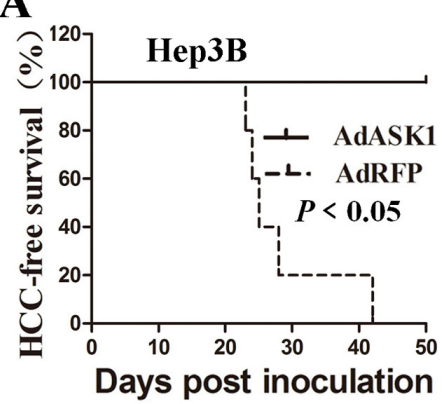

D

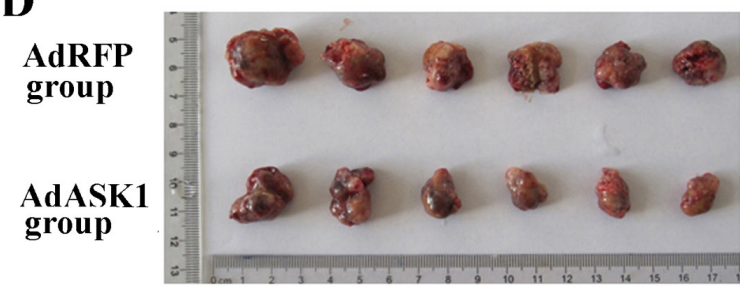

B

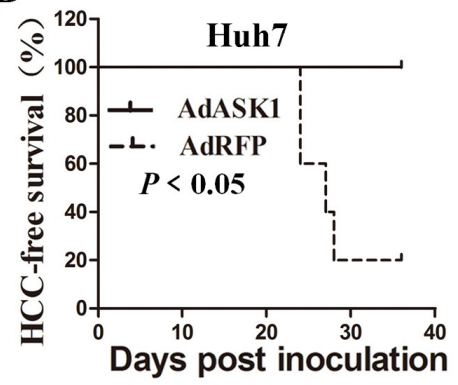

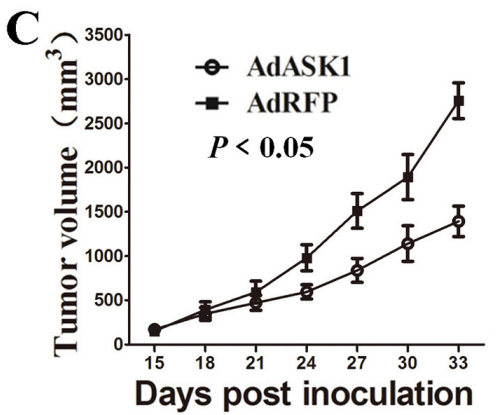

Days post inoculation
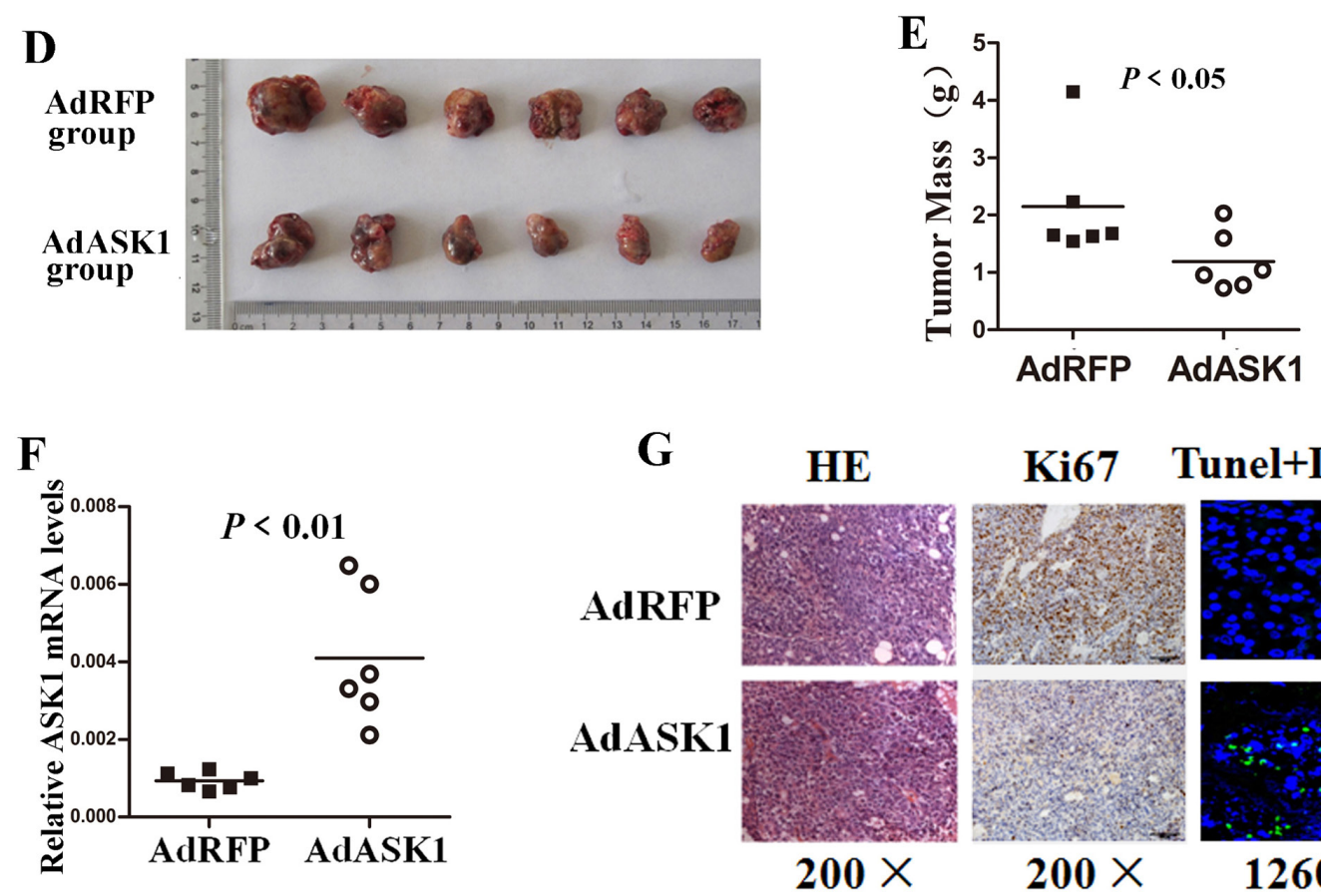

Ki67 Tunel+DAPI

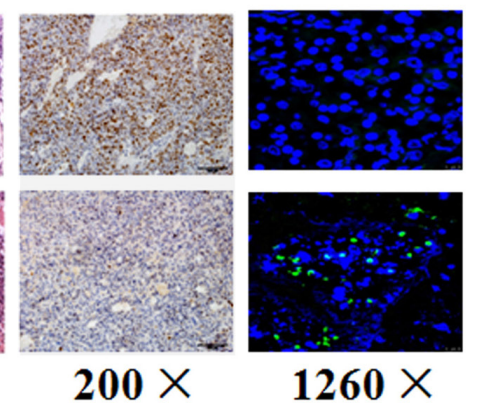

Figure 4: ASK1 overexpression suppresses tumorigenicity of HCC cells in mice. (A, B) HCC-free survival in mice injected with AdASK1- or AdRFP-infected Hep3B (A) and Huh7 cells (B) was analyzed by the Kaplan-Meier method and compared using the log-rank test $(n=5)$. (C-E) Intratumoral AdASK1 injection repressed HCC xenograft growth. A subcutaneous liver tumor model was established based on Huh7 cell implantation. HCC xenografts were then injected with AdASK1 or AdRFP virus. Tumor size was estimated by serial calculation (C) and tumor weight was measured at the endpoint (D, E) $(n=6)$. (F) RT-PCR analysis of ASK1 mRNA expression in Huh7 tumor nodules injected with AdASK1 or AdRFP. (G) Representative images of H \& E stained, Ki67 immunohistochemistry and tunel stained of serial sections from Huh7 tumor nodules injected with AdASK1 or AdRFP. Magnification, $\times 200$ and $\times 1260$; Data in C are shown as the mean $\pm \mathrm{SD}$. Horizontal lines in $\mathrm{E}$ and $\mathrm{F}$ indicate the median values. 
ASK1 has been linked to a variety of cellular functions and pathophysiological processes, such as proliferation, survival, and the inflammatory response [38, 39]. Most importantly, the role of ASK1 in cell differentiation has been studied with great interest in recent years [21, 22, 40-42]. Previous studies have shown that ASK1 was involved in the differentiation process not only of stem/progenitor cells but also of terminally differentiated cells [19, 21, 41], suggesting the core role of ASK1 on differentiation. However, these studies merely found altered ASK1 expression during the cell differentiation process. There is no direct evidence to certify the participation of ASK1 in cell differentiation, especially in HCC cell differentiation. Herein we report that ASK1 inhibited the malignant properties of HCC cells. More intriguingly, and consistent with the effect of $\mathrm{HNF} 4 \alpha$, ectopic ASK1 expression also re-established the normal expression profile of hepatocyte marker genes. Together, these findings first demonstrate the effect of ASK1 on HCC differentiation, which extends our knowledge of ASK1 in cancer. Whether ASK1 has similar differentiation action on other tumors is worth further evaluation.

The p38 MAPKs is predominantly activated through its phosphorylation by ASK1. Activated p38

A
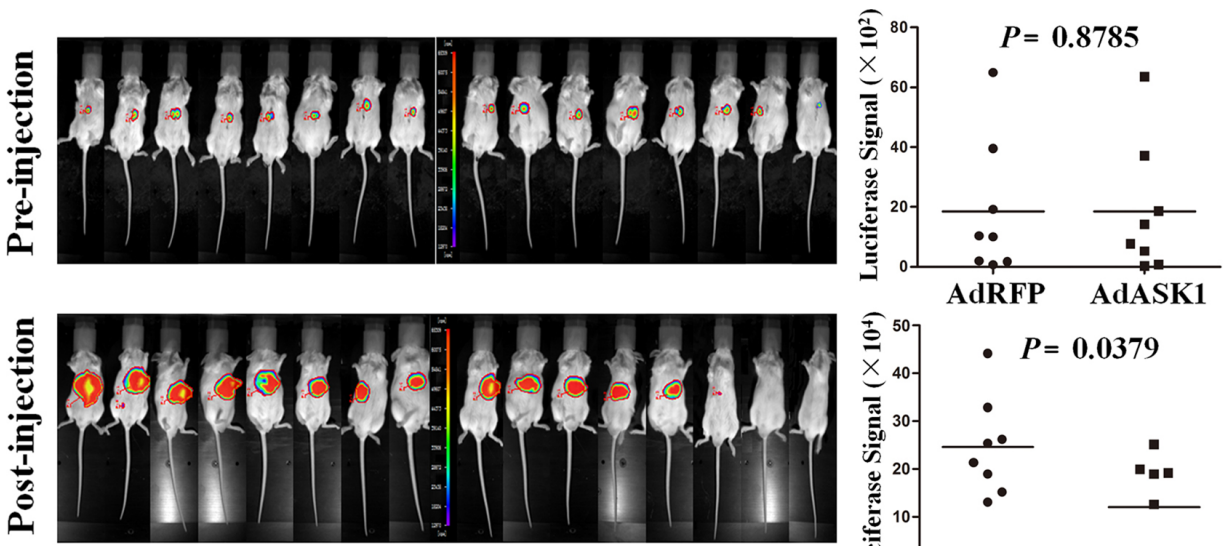

AdRFP

AdASK1

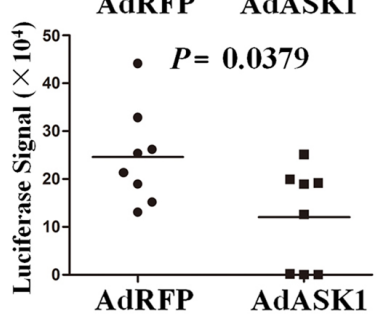

B

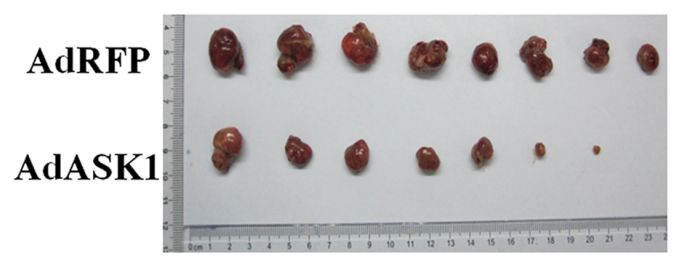

$\mathrm{C}$

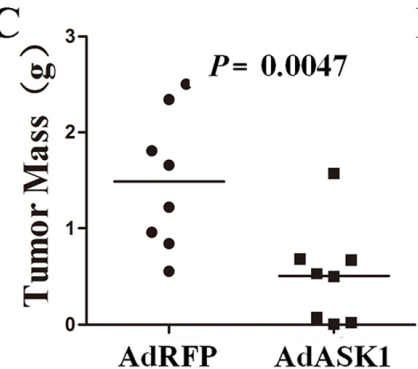

$\mathbf{E}$

AdRFP

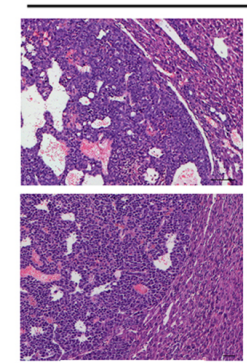

$100 \times$
HE

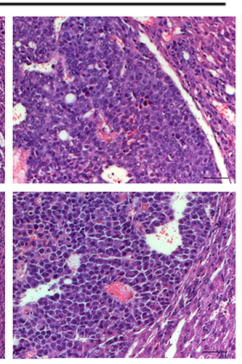

$200 \times$

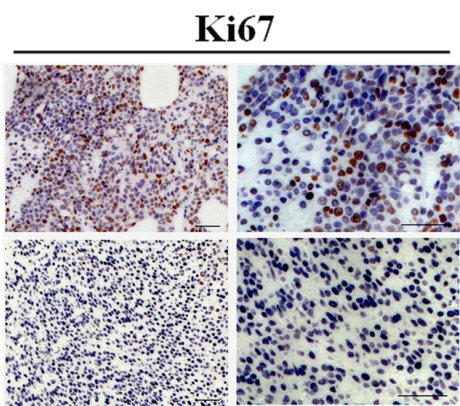

$200 \times$

$400 \times$

D

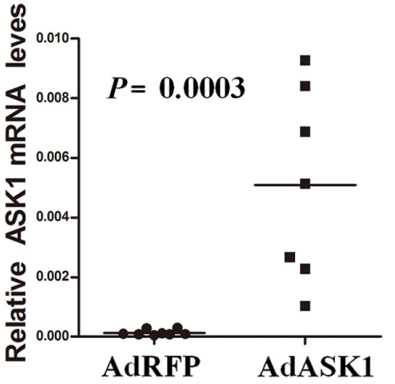

Tunel+DAPI

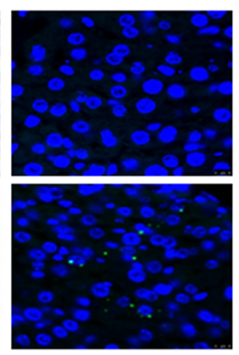

$1260 \times$

Figure 5: Systemic injection of AdASK1 suppresses orthotopic hepatocellular carcinoma growth. (A) Images (left) and statistical analysis (right) of luciferase signals of the experiment in BALB/c nude mice transplanted with Huh7 cells stably expressing luciferase. An orthotopic HCC model was established based on implantation of Huh7 tumor piece into the liver, and then AdASK1 or AdRFP injection through tail vein ( $n=8$ in each group). (B) Images of tumor nodules with systemically injected AdASK1 or AdRFP at the endpoint. (C) Tumor weight measured at the endpoint. (D) RT-PCR analysis of ASK1 mRNA expression in tumor nodules systemically injected with AdASK1 or AdRFP. (E) Representative images of H \& E stained, Ki67 immunohistochemistry and tunel stained of serial sections from tumor nodules systemically injected with AdASK1 or AdRFP. Magnification, $\times 100, \times 200, \times 400$ and $\times 1260$; Horizontal lines in $\mathrm{A}, \mathrm{C}$, and $\mathrm{D}$ indicate the median value. 
A
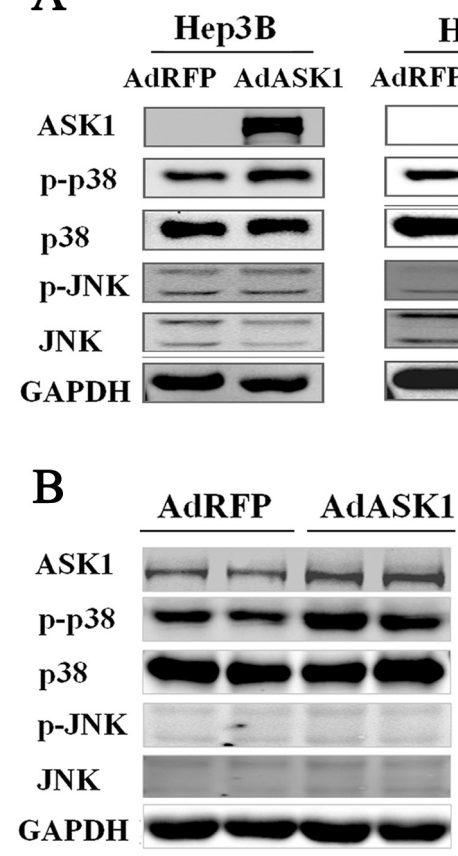

C
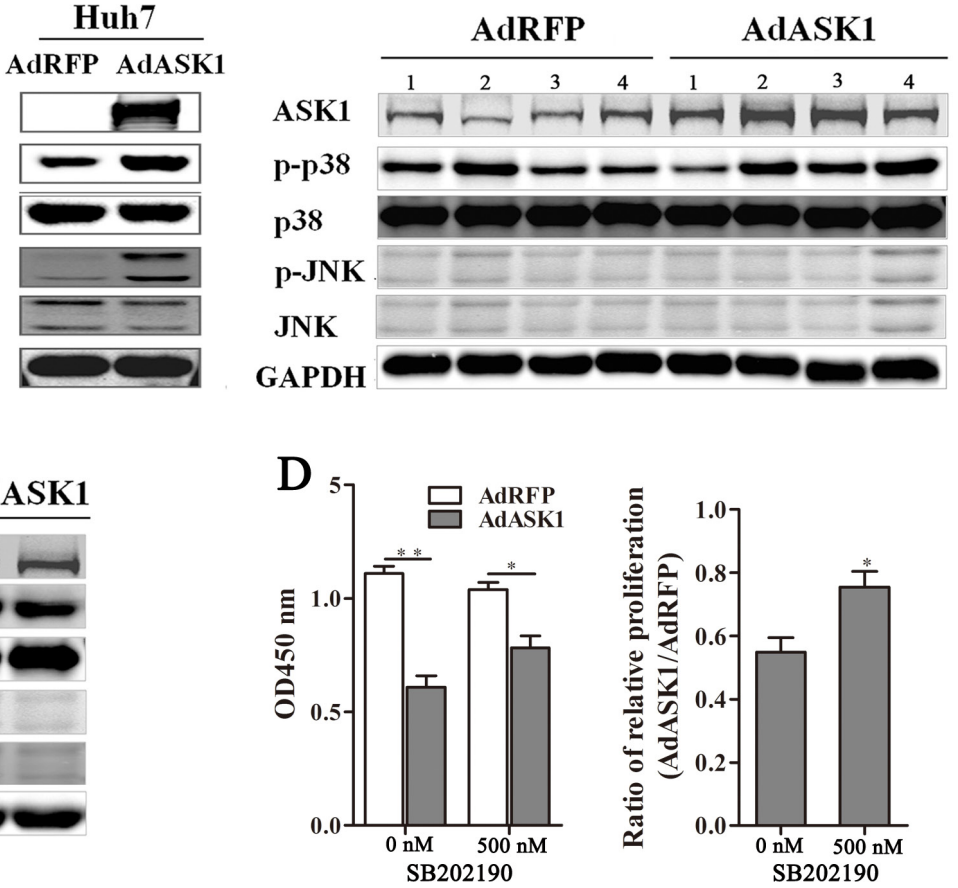

Figure 6: ASK1 overexpression increases p38 phosphorylation. (A) Western blot analysis of ASK1, p-p38, p38, p-JNK, and JNK expression in AdASK1-infected Hep3B and Huh7 cells. (B) Western blot analysis of ASK1, p-p38, p38, p-JNK, and JNK expression in the Huh7 tumor nodules intratumorally injected with AdASK1 or AdRFP. (C) Western blot analysis of ASK1, p-p38, p38, p-JNK, and JNK expression in orthotopic HCC model mice systemically injected with AdASK1 or AdRFP. (D) Cell proliferation of Hep3B cells incubated with p38 inhibitor SB202190 after AdASK1 infected. Data represent the mean $\pm \mathrm{SD}, * P<0.05, * * P<0.01$.
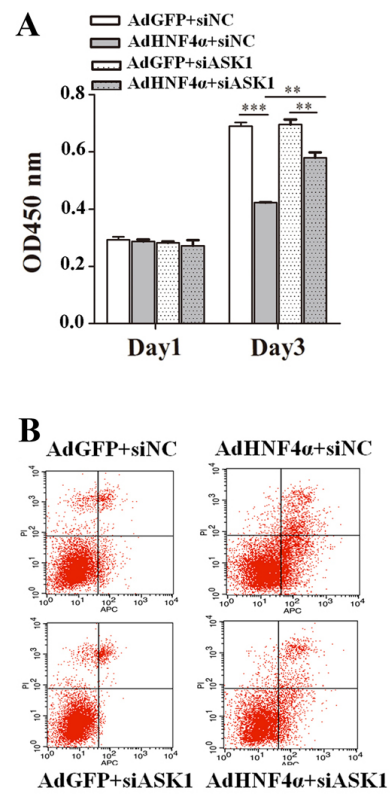
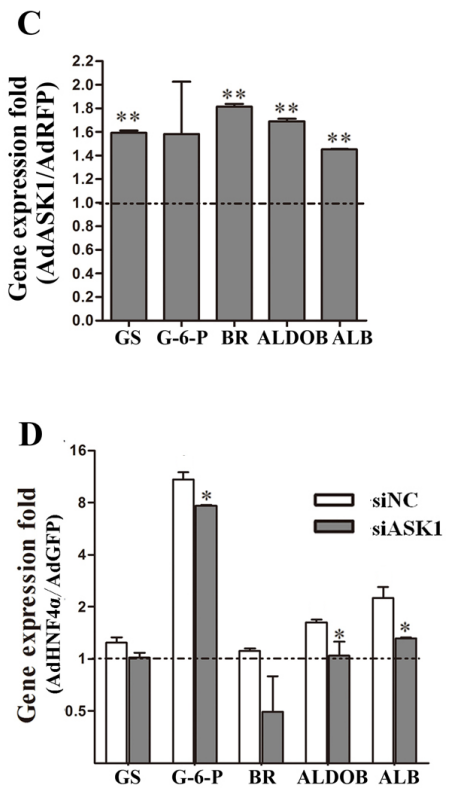

Figure 7: HNF4a suppresses HCC tumorigenicity partly through ASK1 upregulation. (A) Hep3B cells infected with AdHNF4 $\alpha$ or AdGFP were transfected with siASK1 or siNC. Cell proliferation was measured on day 1 and 3 after transfection. (B) Flow cytometric analysis of Hep3B cells infected with AdHNF4 $\alpha$ or AdGFP and then transfected with siASK1 or siNC. (C) Gene expression folds of some hepatocyte marker genes in AdASK1-infected Hep3B cells versus the AdRFP-infected group. Significant increases in expression of characteristic hepatocyte markers included glutamine synthetase (GS), biliverdin reductase (BR), aldolase B (ALDOB) and albumin (ALB). (D) RT-PCR analysis of mRNA expression for some hepatocyte marker genes in HNF4a-overexpressing and siASK1transfected Hep3B cells. Significant difference were observed in expression of glucose-6-phosphatase (G-6-P), ALDOB and ALB. Each value represents the relative ratio of AdHNF4 $\alpha$ to AdGFP. Data represent the mean $\pm \mathrm{SD},{ }^{*} P<0.05,{ }^{* *} P<0.01,{ }^{* * *} P<0.001$. 
was originally considered part of a classic proapoptotic pathway $[26,43,44]$. Nevertheless, substantial evidence has also established a unique role for p38 MAPK in cell differentiation [41, 42, 45-48]. With this study, p38 pathway was obviously activated by ASK1. Moreover, the p38 inhibitor partially antagonized the effect of ASK1 or HNF $4 \alpha$ overexpression on cell proliferation. Thus, we could conclude that the p38 pathway participate the $\mathrm{HNF} 4 \alpha$-induced $\mathrm{HCC}$ differentiation. In addition to $\mathrm{p} 38$, the JNK pathway, another downstream pathway of ASK1, also has an important role in mesenchymal stem cell differentiation [49]. Whether JNK was participated in this process need to be further studied in future.

In conclusion, the present work first reports the prognostic value of ASK1 in HCC patients and certifies its differentiation and suppressive effect on HCC. These data further broaden our understanding of ASK1 biological function and suggests a novel target for HCC therapy.

\section{MATERIALS AND METHODS}

More details are presented in the Supplementary Materials and Methods.

\section{Adenoviral vectors}

The recombinant adenoviruses AdHNF4 $\alpha$ and the control virus AdGFP were previously constructed in our laboratory [13]. The ASK1 expression plasmid was obtained from the DNA Resource Core of Harvard University. Replication-deficient recombinant adenoviruses AdASK1 and the AdRFP control were constructed by Shanghai Sunbio Medical Biotechnology (Shanghai, China).

\section{cDNA microarray analysis}

Hep3B cells were harvested $72 \mathrm{~h}$ after infection with AdHNF4 $\alpha$ or AdGFP at a multiplicity of infection of 100. Total RNA was extracted and used to prepare cDNA probes. cDNA microarrays (Affymetrix U133 plus 2.0 Array) were used to generate differential gene expression profiles, and image processing and data analysis were performed using Affymetrix GeneChip Scanner 3000 and GeneChip Operating Software. The differential genes were subjected to the KEGG pathway analysis performed with DAVID software [33].

\section{Patient tissue specimens and microarray analysis}

A total of $60 \mathrm{HCC}$ tissue samples paired with surrounding noncancerous tissues were obtained from patients who underwent surgical resection at the Eastern Hepatobiliary Surgery Hospital and Changzheng Hospital (Shanghai, China). HNF4 $\alpha$ and ASK1 expression were measured by RT-PCR. A tissue microarray block containing 90 HCCs along with case-matched noncancerous surrounding tissue samples was constructed using a tissue microarrayer. Immunostaining of tissue microarray slides was performed using an anti-ASK1 antibody (CST, Boston, MA, USA). Nuclear ASK1 staining was assessed on a four-point scale (negative, 1; weakly positive, 2; positive, 3 ; strong positive, 4 ) according to the percentage of positively stained cells and the nuclear staining intensity. The immunostaining score was obtained by multiplying the nuclear staining intensity by the percentage of positively stained cells. OS refers to the time to death after surgery. Written informed consent and approval by the Ethics Committee of Second Military Medical University, Shanghai, China, were obtained for all human experiments.

\section{Chromatin immunoprecipitation assays}

ChIP assays were performed essentially as previously described [15]. Briefly, Hep3B cells were crosslinked and processed according to the ChIP Assay Kit protocol (Millipore, Boston, USA). Anti-HNF4 $\alpha$ primary antibody or control IgG was used for immunoprecipitation experiments. RT-PCR analysis was carried out for HNF4 $\alpha$ binding sites in $A S K 1$ promoter. The predicted HNF4 $\alpha-$ binding sites on $A S K 1$ gene were analyzed by JASPAR, a high-quality transcription factor binding profile database [34]. The sequence of the putative binding site of HNF4 $\alpha$ in $A S K 1$ promoter and RT-PCR primers are listed in Supplementary Figure S3 and Table S1. At least three independent experiments were performed.

\section{Luciferase reporter assay}

To assess the effect of HNF4 $\alpha$ expression on $A S K 1$ promoter activity, the $A S K 1$ promoter sequence containing the predicted HNF4 $\alpha$-binding sites was PCR amplified from Hep3B genomic DNA and cloned into the pGL3promoter luciferase vector. A mutated reporter carrying disrupted binding sites was generated by PCR-directed mutagenesis.

Hep3B and Huh7 cells growing in 24-well plates were first infected with HNF4 $\alpha$ adenovirus and then transfected with $A S K 1$ promoter vectors together with the control pRL-SV40 vector. Luciferase activity was measured using the Dual-Glo Luciferase Assay System (E2920; Promega) at $48 \mathrm{~h}$ post-transfection. At least three independent experiments were carried out for each condition.

\section{Cell proliferation and colony formation assays}

To test the inhibitory effect of ASK1 on HCC cell proliferation, transfected or infected HCC cells were plated into 24-well plates overnight and then seeded at $4 \times 10^{3} /$ well into triplicate wells of a 96 -well plate. Cell proliferation was assessed using Cell Counting Kit-8 (Dojindo, Tokyo, Japan). For colony formation assays, 
Hep3B and Huh7 cells infected or transfected for $6 \mathrm{~h}$ were seeded into $60-\mathrm{mm}$ dishes and grown in culture medium for approximately 2 weeks. Colonies were then fixed with $4 \%$ paraformaldehyde and visualized by crystal violet staining.

\section{Flow cytometry}

To quantify cellular apoptosis, adenovirus-infected HCC cells were stained with an annexin V staining Kit (Bestbio, Beijing, China) according to the manufacturer's protocol and analyzed by flow cytometry. Apoptotic cells were defined as annexin-V-positive cells. Three independent experiments were carried out.

\section{Migration and invasion assay}

For cell migration and invasion assays, transfected or infected cells were seeded at $5 \times 10^{4} /$ transwell into the upper chamber (BD Bioscience, New Jersey, USA) with or without matrigel-coated membrane under serumfree conditions. The bottom chamber was contained by medium supplemented with $10 \%$ fetal bovine serum. After incubation for 24 or $48 \mathrm{~h}$, cells in the upper chamber were carefully removed and cells adhering to the underside of the membrane were stained with crystal violet and at least five fields per sample were photographed under inverted microscopy. Cell migration and invasion were measured using image analysis software (Image-Pro Plus 6.0; Media Cybernetics). At least three independent experiments were performed for each condition.

\section{Animal models}

Male BALC/c nude mice or NOD/SCID mice of 4-6 weeks of age were used in this study (Shanghai SLAC Laboratory Animal Company). To detect the effect of ASK1 overexpression on HCC cell tumorigenicity, Hep3B or Huh7 cells infected with AdASK1 or AdRFP were inoculated subcutaneously into both flanks of each BALB/c nude mouse $(n=6)$. Tumor formation, size (volume $=0.5 \times$ width $^{2} \times$ length $)$, and final weight were assessed. To investigate the suppressive effect of ASK1, a subcutaneously implanted HCC model was established by injecting $2 \times 10^{6} \mathrm{Huh} 7$ cells into the armpits of nude mice. When the tumor volume reached about $200 \mathrm{~mm}^{3}$, mice were randomly assigned to treatment and control groups, and intratumorally injected with AdASK1 or AdRFP twice a week for up to 3 weeks. The kinetics of tumor formation was estimated. At the time of euthanasia, tumors were removed for further analysis.

To further explore the effect of ASK1 overexpression in vivo, Huh7 cells labelled with luciferase gene were used to establish subcutaneous tumors, as previously described $[16,50]$. Once each tumor reached $500 \mathrm{~mm}^{3}$, it was removed and cut into $1-\mathrm{mm}^{3}$ pieces. Subsequently, tumor pieces were implanted into the livers of NOD/SCID mice to mimic primary HCCs. After a week, mice were assigned into two groups matched according to luciferase burden; hereafter, AdASK1 or AdRFP was injected into the tail vein twice a week for up to 3 weeks. Bioluminescence was measured after intraperitoneal injection with D-luciferin ( $5 \mu \mathrm{L} / \mathrm{g}$ body weight) and bioluminescent images were acquired using the NightOWL imaging system (Berthold LB983, Berthold Technologies, Germany).

All animal experiments were performed at the Second Military Medical University according to protocols approved by the institutional animal care committee.

\section{Immunohistochemistry and TUNEL assay}

Tissue samples were fixed in formaldehyde solution and embedded in paraffin, and then serial sections were cut. Tissue samples were subjected to hematoxylin and eosin (H \& E) staining for standard histologic examination and to immunohistochemical examination for $\mathrm{HNF} 4 \alpha$, ASK1, p-ASK1 and Ki67 expression. For TUNEL staining, paraffin-embedded tissue samples were analyzed using a One Step TUNEL Apoptosis Assay Kit (Beyotime, Jiangsu, China). Images were acquired using a Leica confocal microscope and analyzed with dedicated software (Leica Microsystems).

\section{Statistical analysis}

Statistical analysis was performed using SPSS software (16.0 version) with a $P<0.05$ considered significant. Student's $t$-tests were used to analyze experimental data involving only two groups. Statistical comparisons of more than two groups were evaluated using one-way analysis of variance. Unequal variances pairing were performed using the Wilcoxon signed rank test or the Mann-Whitney $U$ test. The chi-square test was used to compare two sample rates. The Kaplan-Meier method was used to calculate the survival time, and its significance was determined with log-rank test. ${ }^{*} P<0.05$; $* * P<0.01 ; * * * P<0.001$.

\section{GRANT SUPPORT}

This work was supported by the National Natural Science Foundation of China (81270033 to Chuan Yin; Key Program 81230011 to Wei-Fen Xie; Creative Research Groups 81521091 to Wei-Fen Xie) and a Foundation for the Author of National Excellent Doctoral Dissertation of China (201477 to Chuan Yin).

\section{CONFLICTS OF INTEREST}

No potential conflicts of interest were disclosed by the authors. 


\section{REFERENCES}

1. Jemal A, Bray F, Center MM, Ferlay J, Ward E, Forman D. Global cancer statistics. CA Cancer J Clin. 2011; 61:69-90.

2. Tung-Ping Poon R, Fan ST, Wong J. Risk factors, prevention, and management of postoperative recurrence after resection of hepatocellular carcinoma. Ann Surg. 2000; 232:10-24.

3. Santangelo L, Marchetti A, Cicchini C, Conigliaro A, Conti B, Mancone C, Bonzo JA, Gonzalez FJ, Alonzi T, Amicone L, Tripodi $\mathrm{M}$. The stable repression of mesenchymal program is required for hepatocyte identity: a novel role for hepatocyte nuclear factor 4 $\alpha$. Hepatology. 2011; 53:2063-2074.

4. Battle MA, Konopka G, Parviz F, Gaggl AL, Yang C, Sladek FM, Duncan SA. Hepatocyte nuclear factor 4alpha orchestrates expression of cell adhesion proteins during the epithelial transformation of the developing liver. Proc Natl Acad Sci U S A. 2006; 103:8419-8424.

5. Yamagata K, Furuta H, Oda N, Kaisaki PJ, Menzel S, Cox NJ, Fajans SS, Signorini S, Stoffel M, Bell GI. Mutations in the hepatocyte nuclear factor-4alpha gene in maturity-onset diabetes of the young (MODY1). Nature. 1996; 384:458-460.

6. Weissglas-Volkov D, Huertas-Vazquez A, Suviolahti E, Lee J, Plaisier C, Canizales-Quinteros S, Tusie-Luna T, Aguilar-Salinas C, Taskinen MR, Pajukanta P. Common hepatic nuclear factor-4alpha variants are associated with high serum lipid levels and the metabolic syndrome. Diabetes. 2006; 55:1970-1977.

7. Ahn SH, Shah YM, Inoue J, Morimura K, Kim I, Yim S, Lambert G, Kurotani R, Nagashima K, Gonzalez FJ, Inoue Y. Hepatocyte nuclear factor 4alpha in the intestinal epithelial cells protects against inflammatory bowel disease. Inflamm Bowel Dis. 2008; 14:908-920.

8. Darsigny M, Babeu JP, Seidman EG, Gendron FP, Levy E, Carrier J, Perreault N, Boudreau F. Hepatocyte nuclear factor-4alpha promotes gut neoplasia in mice and protects against the production of reactive oxygen species. Cancer Res. 2010; 70:9423-9433.

9. Hatziapostolou M, Polytarchou C, Aggelidou E, Drakaki A, Poultsides GA, Jaeger SA, Ogata H, Karin M, Struhl K, Hadzopoulou-Cladaras M, Iliopoulos D. An HNF4 $\alpha$-miRNA inflammatory feedback circuit regulates hepatocellular oncogenesis. Cell. 2011; 147:1233-1247.

10. Walesky C, Edwards G, Borude P, Gunewardena S, O’Neil M, Yoo B, Apte U. Hepatocyte nuclear factor 4 alpha deletion promotes diethylnitrosamine-induced hepatocellular carcinoma in mice. Hepatology. 2013; 57:2480-2490.

11. Ning BF, Ding J, Yin C, Zhong W, Wu K, Zeng X, Yang W, Chen YX, Zhang JP, Zhang X, Wang HY, Xie WF. Hepatocyte nuclear factor 4 alpha suppresses the development of hepatocellular carcinoma. Cancer Res. 2010; 70:7640-7651.

12. Ning BF, Ding J, Liu J, Yin C, Xu WP, Cong WM, Zhang Q, Chen F, Han T, Deng X, Wang PQ, Jiang CF, Zhang JP, et al. Hepatocyte nuclear factor 4-nuclear facto- $\kappa \mathrm{B}$ feedback circuit modulates liver cancer progression. Hepatology. 2014; 60:1607-1619.

13. Yin C, Lin Y, Zhang X, Chen YX, Zeng X, Yue HY, Hou JL, Deng X, Zhang JP, Han ZG, Xie WF. Differentiation therapy of hepatocellular carcinoma in mice with recombinant adenovirus carrying hepatocyte nuclear factor-4alpha gene. Hepatology. 2008; 48:1528-1539.

14. Yue HY, Yin C, Hou JL, Zeng X, Chen YX, Zhong W, Hu PF, Deng X, Tan YX, Zhang JP, Ning BF, Shi J, Zhang X, et al. Hepatocyte nuclear factor 4alpha attenuates hepatic fibrosis in rats. Gut. 2010; 59:236-246.

15. Yin $\mathrm{C}$, Wang $\mathrm{PQ}, \mathrm{Xu}$ WP, Yang $\mathrm{Y}$, Zhang $\mathrm{Q}$, Ning BF, Zhang PP, Zhou WP, Xie WF, Chen WS, Zhang X. Hepatocyte nuclear factor-4a reverses malignancy of hepatocellular carcinoma through regulating miR-134 in the DLK1-DIO3 region. Hepatology. 2013; 58:1964-1976.

16. Xu WP, Yi M, Li QQ, Zhou WP, Cong WM, Yang Y, Ning BF, Yin C, Huang ZW, Wang J, Qian H, Jiang CF, Chen YX, et al. Perturbation of MicroRNA-370/Lin28 homolog A/nuclear factor kappa B regulatory circuit contributes to the development of hepatocellular carcinoma. Hepatology. 2013; 58:1977-1991.

17. Matsuzawa A, Ichijo H. Stress-responsive protein kinases in redox-regulated apoptosis signaling. Antioxid Redox Signal. 2005; 7:472-481.

18. Al Ghouleh I, Frazziano G, Rodriguez AI, Csányi G, Maniar S, St Croix CM, Kelley EE, Egaña LA, Song GJ, Bisello A, Lee YJ, Pagano PJ. Aquaporin 1, Nox1, and Ask1 mediate oxidant-induced smooth muscle cell hypertrophy. Cardiovasc Res. 2013; 97:134-142.

19. Sayama K, Hanakawa Y, Shirakata Y, Yamasaki K, Sawada Y, Sun L, Yamanishi K, Ichijo H, Hashimoto K. Apoptosis signalregulating kinase 1 (ASK1) is an intracellular inducer of keratinocyte differentiation. J Biol Chem. 2001; 276:999-1004.

20. Eaton GJ, Zhang QS, Diallo C, Matsuzawa A, Ichijo H, Steinbeck MJ, Freeman TA. Inhibition of apoptosis signalregulating kinase 1 enhances endochondral bone formation by increasing chondrocyte survival. Cell Death Dis. 2014; 5:e1522.

21. Song J, Cho KJ, Cheon SY, Kim SH, Park KA, Lee WT, Lee JE. Apoptosis signal-regulating kinase 1 (ASK1) is linked to neural stem cell differentiation after ischemic brain injury. Exp Mol Med. 2013; 45:e69.

22. Zeng T, Peng L, Chao H, Xi H, Fu B, Wang Y, Zhu Z, Wang G. IRE1 $\alpha$-TRAF2-ASK1 complex-mediated endoplasmic reticulum stress and mitochondrial dysfunction contribute to CXC195-induced apoptosis in human bladder carcinoma T24 cells. Biochem Biophys Res Commun. 2015 Mar 19.

23. Ishaq M, Kumar S, Varinli H, Han ZJ, Rider AE, Evans MD, Murphy AB, Ostrikov K. Atmospheric gas plasma-induced ROS production activates TNF-ASK1 pathway for the induction of melanoma cancer cell apoptosis. Mol Biol Cell. 2014; 25:1523-1531. 
24. Kuo PL, Chen CY, Hsu YL. Isoobtusilactone A induces cell cycle arrest and apoptosis through reactive oxygen species/ apoptosis signal-regulating kinase 1 signaling pathway in human breast cancer cells. Cancer Res. 2007;67:7406-7420.

25. Lin FR, Huang SY, Hung $\mathrm{KH}$, Su ST, Chung $\mathrm{CH}$, Matsuzawa A, Hsiao M, Ichijo H, Lin KI. ASK1 promotes apoptosis of normal and malignant plasma cells. Blood. 2012; 120:1039-1047.

26. White DE, Burchill SA. Fenretinide-dependent upregulation of death receptors through ASK1 and p38 $\alpha$ enhances death receptor ligand-induced cell death in Ewing's sarcoma family of tumours. Br J Cancer. 2010; 103:1380-1390.

27. Hayakawa Y, Hirata Y, Nakagawa H, Sakamoto K, Hikiba Y, Otsuka M, Ijichi H, Ikenoue T, Tateishi K, Akanuma M, Ogura K, Yoshida H, Ichijo H, et al. Apoptosis signal-regulating kinase 1 regulates colitis and colitis-associated tumorigenesis by the innate immune responses. Gastroenterology. 2010; 138:1055-1067.

28. Iriyama $\mathrm{T}$, Takeda $\mathrm{K}$, Nakamura $\mathrm{H}$, Morimoto $\mathrm{Y}$, Kuroiwa $\mathrm{T}$, Mizukami J, Umeda T, Noguchi T, Naguro I, Nishitoh H, Saegusa K, Tobiume K, Homma T, et al. ASK1 and ASK2 differentially regulate the counteracting roles of apoptosis and inflammation in tumorigenesis. EMBO J. 2009; 28:843-53.

29. Hayakawa Y, Hirata Y, Nakagawa H, Sakamoto K, Hikiba Y, Kinoshita H, Nakata W, Takahashi R, Tateishi K, Tada M, Akanuma M, Yoshida H, Takeda K, et al. Apoptosis signalregulating kinase 1 and cyclin $\mathrm{D} 1$ compose a positive feedback loop contributing to tumor growth in gastric cancer. Proc Natl Acad Sci U S A. 2011; 108:780-785.

30. Hayakawa Y, Hirata Y, Sakitani K, Nakagawa H, Nakata W, Kinoshita H, Takahashi R, Takeda K, Ichijo H, Maeda S, Koike K. Apoptosis signal-regulating kinase-1 inhibitor as a potent therapeutic drug for the treatment of gastric cancer. Cancer Sci. 2012; 103:2181-2185.

31. Nakagawa H, Hirata Y, Takeda K, Hayakawa Y, Sato T, Kinoshita H, Sakamoto K, Nakata W, Hikiba Y, Omata M, Yoshida H, Koike K, Ichijo H, Maeda S. Apoptosis signalregulating kinase 1 inhibits hepatocarcinogenesis by controlling the tumor-suppressing function of stress-activated mitogenactivated protein kinase. Hepatology. 2011; 54:185-195.

32. Lin H, Yan J, Wang Z, Hua F, Yu J, Sun W, Li K, Liu H, Yang H, Lv Q, Xue J, Hu ZW. Loss of immunity-supported senescence enhances susceptibility to hepatocellular carcinogenesis and progression in Toll-like receptor 2-deficient mice. Hepatology. 2013; 57:171-182.

33. Huang da W, Sherman BT, Lempicki RA. Systematic and integrative analysis of large gene lists using DAVID bioinformatics resources. Nat Protoc. 2009; 4:44-57.

34. Bryne JC, Valen E, Tang MH, Marstrand T, Winther O, da Piedade I, Krogh A, Lenhard B, Sandelin A. JASPAR, the open access database of transcription factor-binding profiles: new content and tools in the 2008 update. Nucleic Acids Res. 2008; 36:D102-106.

35. Won M, Park KA, Byun HS, Sohn KC, Kim YR, Jeon J, Hong JH, Park J, Seok JH, Kim JM, Yoon WH, Jang IS,
Shen HM, et al. Novel anti-apoptotic mechanism of A20 through targeting ASK1 to suppress TNF-induced JNK activation. Cell Death Differ. 2010; 17:1830-1841

36. Wang ZY, Eric P Bishop, Peter A Burke. Expression profile analysis of the inflammatory response regulated by hepatocyte nuclear factor $4 \alpha$. BMC Genomics. 2011; 12: 128.

37. Odom DT, Zizlsperger N, Gordon DB, Bell GW, Rinaldi NJ, Murray HL, Volkert TL, Schreiber J, Rolfe PA, Gifford DK, Fraenkel E, Bell GI, Young RA. Control of pancreas and liver gene expression by HNF transcription factors. Science. 2004; 303:1378-1381.

38. Ichijo $H$, Nishida E, Irie $K$, ten Dijke $P$, Saitoh $M$, Moriguchi T, Takagi M, Matsumoto K, Miyazono K, Gotoh Y. Induction of apoptosis by ASK1, a mammalian MAPKKK that activates SAPK/JNK and p38 signaling pathways. Science. 1997; 275:90-94.

39. Matsuzawa A, Saegusa K, Noguchi T, Sadamitsu C, Nishitoh H, Nagai S, Koyasu S, Matsumoto K, Takeda K, Ichijo H. ROS-dependent activation of the TRAF6ASK1-p38 pathway is selectively required for TLR4mediated innate immunity. Nat Immunol. 2005; 6:587-592.

40. Takeda K, Hatai T, Hamazaki TS, Nishitoh H, Saitoh M, Ichijo H. Apoptosis signal-regulating kinase 1 (ASK1) induces neuronal differentiation and survival of PC12 cells. J Biol Chem. 2000; 275:9805-9813.

41. Faigle R, Brederlau A, Elmi M, Arvidsson Y, Hamazaki TS, Uramoto H, Funa K. ASK1 inhibits astroglial development via $\mathrm{p} 38$ mitogen-activated protein kinase and promotes neuronal differentiation in adult hippocampus-derived progenitor cells. Mol Cell Biol. 2004; 24:280-293.

42. Tran P, Ho SM, Kim BG, Vuong TA, Leem YE, Bae GU, Kang JS. TGF- $\beta$-activated kinase 1 (TAK1) and apoptosis signal-regulating kinase 1 (ASK1) interact with the promyogenic receptor Cdo to promote myogenic differentiation via activation of p38 MAPK pathway. J Biol Chem. 2012; 287:11602-11615.

43. De Zutter GS, Davis RJ. Pro-apoptotic gene expression mediated by the $\mathrm{p} 38$ mitogen-activated protein kinase signal transduction pathway. Proc Natl Acad Sci U S A. 2001; 98:6168-6173.

44. Ghatan S, Larner S, Kinoshita Y, Hetman M, Patel L, Xia Z, Youle RJ, Morrison RS. p38 MAP kinase mediates bax translocation in nitric oxide-induced apoptosis in neurons. J Cell Biol. 2000; 150:335-347.

45. Liu Y, Zheng WK, Gao WS, Shen Y, Ding WY. Function of TGF-beta and p38 MAKP signaling pathway in osteoblast differentiation from rat adipose-derived stem cells. Eur Rev Med Pharmacol Sci. 2013; 17:1611-1619.

46. Yang J, Ye L, Hui TQ, Yang DM, Huang DM, Zhou XD, Mao JJ, Wang CL. Bone morphogenetic protein 2-induced human dental pulp cell differentiation involves p38 mitogen-activated protein kinase-activated canonical WNT pathway. Int J Oral Sci. 2015; 7:95-102.

47. Zhang X, Zhou C, Zha X, Xu Z, Li L, Liu Y, Xu L, Cui L, $\mathrm{Xu}$ D, Zhu B. Apigenin promotes osteogenic differentiation 
of human mesenchymal stem cells through JNK and p38 MAPK pathways. Mol Cell Biochem. 2015; 407:41-50.

48. Gardner S, Gross SM, David LL, Klimek JE, Rotwein P. Separating myoblast differentiation from muscle cell fusion using IGF-I and the p38 MAP kinase inhibitor SB202190. Am J Physiol Cell Physiol. 2015:ajpcell.00184.2015.

49. Hwang JH, Byun MR, Kim AR, Kim KM, Cho HJ, Lee YH, Kim J, Jeong MG, Hwang ES, Hong JH. Extracellular Matrix Stiffness Regulates Osteogenic Differentiation through MAPK Activation. PLoS One. 2015; 10:e0135519.
50. Wang J, Zhu CP, Hu PF, Qian H, Ning BF, Zhang Q, Chen F, Liu J, Shi B, Zhang X, Xie WF. FOXA2 suppresses the metastasis of hepatocellular carcinoma partially through matrix metalloproteinase-9 inhibition. Carcinogenesis. 2014; 35:2576-2583. 